\title{
Goodwill and Dynamic Advertising Strategies
}

\author{
Toker Doganoglu*and Daniel Klapper ${ }^{\dagger}$
}

March 14, 2005

\begin{abstract}
In this paper, we empirically analyze weekly advertising policies of manufacturing firms in consumer goods markets. We assume firms engage in persuasive advertising, thus policies of firms affect the goodwill of a brand. We introduce a demand and a goodwill production function. A simple transformation of the demand function allows us to identify not only the demand parameters but also the parameters of the goodwill production function. We reconstruct the unobserved goodwill levels using these parameters and past advertising levels. We restrict our attention to Markov Perfect Equilibrium strategies which are functions of payoff relevant state variables. Without imposing further restrictions on the dynamic competitive environment, we investigate the relationship between observed advertising strategies-which are assumed to be MPE - and payoff relevant state variables by means of several reduced form specifications. The most important determinant of advertising intensity turns out to be goodwill. We demonstrate that controlling for an ad campaign significantly improves the explanatory power of the model.
\end{abstract}

JEL Classification: D21, L15,M37.

Keywords: advertising strategies, goodwill, markov perfect equilibrium.

${ }^{*}$ Center for Information and Network Economics, University of Munich, Akademiestr. 1/I, 80799 Munich, Germany. email: toker@stat.uni-muenchen.de

${ }^{\dagger}$ Christian-Albrechts-Universität zu Kiel,Lehrstuhl für Absatzwirtschaft, Westring 425, D-24098 Kiel, Germany 


\section{Introduction}

In many consumer goods markets, observed television advertising policies follow interesting patterns, especially at a weekly level. Firms tend to advertise for a certain number of weeks, and cease advertising activity for a few months and then start again. This pattern seems to hold for a variety of product groups such as the liquid detergents which we analyze here, or frozen food items as analyzed in Dube, Hitsch and Manchanda (2003). Viewed at a low frequency, i.e. on a quarter basis, such behavior is consistent with theoretical literature on optimal advertising which promotes pulsing as the policy of choice. However, the high frequency patterns in advertising activity suggests that firms may be following more involved strategies. In this paper, we investigate how the observed behavior may arise. We postulate a model of demand and competitive environment which we use in deriving stylized features of advertising strategies based on an empirical analysis of observed behavior. Our findings should be a useful input in formulating models where the observed advertising behavior could be sustained as equilibrium outcomes.

We start with an axiom on why firms advertise. We assume that advertising is persuasive, that is, firms try increase their brand value by means of advertising. As standard in the literature, this effect is induced by a goodwill stock. Thus, advertising activity affects the level of goodwill stock which in turn shifts the consumer demand. It is presumable that firms base their advertising policies on their goodwill levels among other factors. Unfortunately, goodwill is not directly observable rendering an analysis of the relation between advertising behavior and goodwill complicated if not impossible.

To overcome this problem, we offer a methodology to indirectly infer goodwill levels in this paper. Our strategy is conditional on a demand and a goodwill production function specification. Specifically, we use an aggregate discrete choice model for demand, and a Cobb-Douglas type goodwill production function. Consumer utility, the primitive in the discrete choice model, increases in goodwill at a decreasing rate. ${ }^{1}$ A series of simple transformations of the demand functions allows us to

\footnotetext{
${ }^{1}$ Note that at this stage of our analysis, we remain neutral on how the observed advertising is determined apart from taking into account their potential endogeneity.
} 
measure the incremental effect of current advertising on demand as well as identify parameters of the goodwill production function. Hence, given a sufficient number of observations on advertising activity, we can reconstruct goodwill levels as implied by its effect on the demand.

Our main goal is to describe observed advertising strategies and their relationship to goodwill. In order to accomplish this goal, we briefly describe a dynamic competitive environment in which advertising competition takes place between brands. This model is intended to be a guide rather then a formal model of strategic interaction between the firms which we solve to derive equilibrium policies. Based on this framework, we motivate the use of policies which only depend on the current payoff-relevant state variables, i.e. Markovian policies. Furthermore, this step in our analysis also allows us to identify the appropriate state variables. Not surprisingly, an important determinant of advertising suggested by this model is the goodwill. Using the implied determinants, we perform a reduced form analysis to explain observed advertising behavior.

Our empirical study is performed on the data from the liquid detergent market where firms extensively use TV advertisements to push sales. We estimate a variety of models and confirm our conjecture that goodwill level is an important driver of advertising activity. We provide some new insights on how the timing and duration of ad campaigns are determined. The models where we just use the current level of goodwill turn out to have low explanatory power and the parameter estimates do not always conform with the common sense. We have, as a consequence, estimated a number of different reduced form specifications in order to control for the presence of an additional decision variable firms have to choose: campaign or not. We control whether a firm is in a campaign or not with some variables we construct based on goodwill levels. Thus, the decision to start and to end a campaign is related to the level of goodwill stock. The models estimated with such control variables yield very pleasing results. In addition, they suggest that firms might be following a variant of $(S, s)$ strategies. The difference to the standard $(S, s)$ type policy is the long duration it takes to reach the target level $S$. This however is easily explained by the natural constraints that exist in the number of TV advertising slots.

The remainder of the paper is organized as follows. The next section will describe 
the relationship of our work to the literature. Then, in section three, we outline our general modeling framework, introduce the demand and the goodwill production functions. We also briefly sketch a model of dynamic advertising competition in order to guide our empirical analysis. In section four, we present the empirical study along with the data. We also provide detailed discussions on the key drivers of firms' advertising choice. The paper concludes with a general discussion in section five.

\section{Positioning against related research}

Most consumer goods manufacturers use a large share of their marketing budget for advertising, especially TV-advertisements, to build brand equity and to influence customer preferences. Thus, it is not surprising that a substantial body of research has investigated the impact of advertising on buying behavior, purchase intentions and brand awareness among others (e.g. Vakratsas and Ambler, 1999; Tellis and Weiss, 1995). This stream of research has analyzed what factors determine the advertising effectiveness.

Our paper is closely related to the literature on advertising competition. Papers, in this strand of literature, have modeled advertising competition in a dynamic setting relying on differential game methods (e.g. Chintagunta and Vilcassim, 1992; Deal, 1979; Erickson, 1985, 1995; Fruchter and Kalish, 1997; Sorger, 1988). The open loop or closed loop Nash equilibrium solution is derived to obtain the steadystate optimal advertising spending levels. Most of these studies have limited or no empirical validation for the underlying model (see e.g. Rao, 1990). For example, a very recent paper, Espinosa and Mariel (2001), develops a dynamic model of oligopolistic advertising competition with competitive and informative contents but it does not provide an empirical study. Erickson (1992) and Chintagunta and Vilcassim (1992) are among the few empirical advertising competition models that are based on differential games. These papers adopt a Lanchester model of combat to represent the evolution of the market shares of the two rivals as the function of the own and competitive advertising expenditure level. These methods are usually constrained by the number of competing firms (i.e. two), the shape of the response 
function and the type of general advertising behavior. Moreover, these models do not consider equilibrium in periodic strategies where firms advertise for a few periods and stop advertising for considerably long periods.

The question how firms should allocate their advertising budgets across time, that is engage in a uniform advertising policy or engage in an advertising pulsing policy has led to a vast literature. This literature advocates the important role played by the shape of the advertising response function on dynamic advertising strategies (e.g. Mahajan and Muller, 1986; Mesak and Darrat, 1992; Sasieni, 1989; Vakratsas et al., 2004). In a seminal paper, Sasieni (1971) analytically shows for a monopoly case that if marginal returns of sales to advertising are not increasing, then there exists an "optimal" expenditure level that allows a firm to maintain its optimal sales level. In case of an S-shaped sales response function, the chattering policy yields the highest payoff. Chattering is an abstract, theoretical policy in which a firm alternates an infinite number of times during the finite planning horizon between high and zero levels of advertising. Mahajan and Muller (1986) define pulsing policy where a firm alternates between high and zero levels of advertising in a periodic manner as a feasible approximation to chattering and show that it dominates its practical alternatives in the presence of an S-shaped response function. Feinberg (2001), on the other hand, shows that S-shaped response functions cannot alone account for the empirically observed pulsing policies. He shows that for a broad class of models with S-shaped sales response, the optimal advertising strategy is not periodic and involves constant spending in the long run. Note that these results are typically derived based on very restrictive assumptions, e.g. a monopolist firm. Furthermore, they usually assume relatively simple cost functions such as linear variable costs and, more importantly, fixed costs are assumed away. In contrast to the strand of literature which advocates S-shaped response functions in deriving the optimality of pulsing policies, Hahn and Hyun (1991) show that if the underlying advertising cost function has fixed cost components and satisfies certain conditions, a pulsing-type strategy may be optimal irrespective of the shape of the sales response function. In their model, a periodic advertising policy where a firm spends a constant amount for a portion of the period while stops advertising for the remainder of the period can be sustained as an optimal policy. 
Several papers have explicitly addressed the issue of pulsing-type behavior in the presence of competition. Villas-Boas (1993) studies whether competing firms should alternate between zero and non zero advertising levels in or out of phase. He shows that advertising effectiveness and profits are higher if firms advertise in alternate periods, i.e. out of phase. A series of papers, Mesak and Calloway (1995a, 1995b) and Mesak (1999), investigate alternate advertising scheduling schemes using a game theoretic approach. These papers, based on mostly numerical analysis, find that whether firms engage in a uniform advertising policy or not depend on the shape of the advertising response function. The results from the monopoly case seem to translate to the case of oligopoly with concave response functions. However, there seems to be no clear-cut link between the monopoly and oligopoly results with S-shaped response functions. Even though Mesak (1999) proves the existence of an oligopoly equilibrium with uniform advertising policies with concave response functions, he does not provide a proof ruling out an equilibrium with pulsing policies.

Closest to our paper is Dube, Hitsch and Manchanda (2003) (henceforth DHM) which is very similar in its modeling approach. Both papers start by estimating the parameters of a goodwill production and an advertising response function using a demand specification and both papers adopt logit based discrete choice models. DHM subscribe to the point of view that pulsing arises due to S-shaped response functions, and thus adopts a threshold response model in modeling the goodwill production function. They use the estimated parameter values to calibrate a dynamic game model of advertising competition and derive (numerically) equilibrium advertising strategies. Their results support pulsing in equilibrium where firms alternate between no advertising and high levels of advertising, but nevertheless fail to match certain patterns in observed advertising strategies. Though the selected methodological approach is rich, the model does not account for the fact that firms typically start an ad campaign and then spend the budget for the whole campaign across several successive periods to meet the necessary contacts in the target group in order to build goodwill. We will further discuss the relationship of our paper to DHM after introducing our model. 


\section{Model formulation}

Before introducing the model let us briefly explain the grounds for our modeling choices. Our main goal is to explain observed advertising patterns. In many consumer goods industries advertising budgets are not spend evenly across time but they are concentrated within certain periods. The data exhibits patterns where a relatively long period of high-levels of advertising followed by also relatively long periods of no advertising. This kind of advertising strategy can be classified as pulsing, consistent with the traditional definition of pulsing, as given in Mahajan and Muller (1986), where firms alternate between high and zero levels of advertising. However, observed advertising patterns involve relatively long periods, which contradicts the view that pulsing policies are feasible approximations to chattering policies. Therefore, we prefer to think of the patterns observed as campaigning, instead of pulsing.

One important building block in our modeling approach is our belief on longterm impact of advertising on sales. Furthermore, we assume that advertising is persuasive and firms can increase their brand value by means of advertising. Therefore, we first postulate a model of demand which allows potential long-term effects of advertising through the impact of a goodwill stock on consumer utilities. We also adopt a goodwill production function which governs the dynamic evolution of the goodwill stock. Conditional on the demand and goodwill production function specifications, we then derive an estimation methodology for the model parameters. Using the estimated values of parameters of the goodwill production function and a sufficiently long time series of observed advertising, we can infer the unobserved levels of goodwill.

Facing a demand function which could be effected by advertising, firms will engage in competition not only in prices, but also in advertising which could be thought of as investments that produce a stock of firm (brand) goodwill. In oligopolistic industries, as most consumer goods industries are, advertising may provide a major source of interfirm rivalry, especially to reduce price competition. A basic property of dynamic oligopolistic markets is that competitive behavior of a firm may affect competitors' future choices, especially as the current choices affect the market shares 
of all brands in the industry. Thus, advertising competition is inherently a dynamic strategic interaction - a dynamic game. It is well know that when dynamic games are considered, the potential equilibrium outcomes are many, thus there is an equilibrium selection problem. In this paper, we will adopt Markov Perfect Equilibrium (MPE) as our equilibrium concept as in Dube et al. (2003) and Doraszelski and Markovich (2004) (see also Maskin and Tirole, 1988; Basar and Oldser, 1982).

In a MPE, firms react to payoff relevant state variables such as goodwill stock, advertising costs, etc., that is firms' policies are functions of payoff relevant state variables. Apart from a few special cases, deriving equilibrium policies analytically is not possible in general. Thus, instead of fully specifying a dynamic game and solving it to derive equilibrium advertising policies, as DHM do, we would outline the basic ingredients of a dynamic strategic environment and identify payoff relevant state variables. Then, we use reduced form models based on these variables to explain the observed advertising behavior.

\subsection{Modeling demand}

We use the nested logit model as outlined in McFadden (1978), Cardell (1991), Berry (1994), and Besanko et al. (1998) and modify it to allow advertising to shift sales. Demand is formulated at the individual consumer or household level. It is based on a utility function which describes the benefits of an alternative for a consumer. In our model we group the $J+1$ products in two exhaustive and mutually exclusive sets, $j=0,1, \ldots, J$ (see Berry, 1994, p. 252).

The outside good, $j=0$, is assumed to be the only member of group 0 while all the other products are in group 1. As it is usually done, we restrict the utility of the 'no purchase'-option to zero, i.e. $\delta_{0 t}=0$ and $U_{i 0 t}=\zeta_{i 0 t}$. On the other hand, consumer $i$ 's utility for brand $j$ in period $t$ is therefore given by:

$$
U_{i j t}=\delta_{j t}+\zeta_{i 1 t}+(1-\sigma) \varepsilon_{i j t}
$$

where $\varepsilon_{i j t}$ is an identically and independently distributed extreme value random variable. $\zeta_{i 1}$ is common to all products in group 1 , that is, it represents a taste for the particular product category, and has a distribution function that depends on $\sigma$, 
with $0 \leq \sigma \leq 1 .^{2}$

The mean utility, $\delta_{j t}$, is

$$
\delta_{j t}=\alpha_{j}+\beta p_{j t}+\mu \ln \left(G_{j t}\right)+\sum_{k=1}^{K} \gamma_{k} X_{k j t}+\xi_{j t} .
$$

In (2), the parameters of the net utility do not depend on the individual, that is, we presume a representative consumer. ${ }^{3}$ In this specification, $\alpha_{j}$ is consumers' intrinsic preference for brand $j, \beta$ is the price sensitivity parameter, $p_{j t}$ is the price of brand $j$ in period $t, \mu$ is the advertising sensitivity parameter, $G_{j t}$ is firm j's goodwill stock in period $t, \gamma_{k}$ is the sensitivity to the observed characteristic $X_{k t}$ that varies by product (e.g. a marketing instrument) and $\xi_{j t}$ is the unobserved attribute for brand $j$ in period $t$.

A demand side estimation equation is easily obtained by

$$
\ln \left(\frac{s_{j t}}{s_{0 t}}\right)=\alpha_{j}+\beta p_{j t}+\mu \ln \left(G_{j t}\right)+\sum_{k=1}^{K} \gamma_{k} X_{k j t}+\sigma \ln \left(s_{j t \mid g}\right)+\xi_{j t}
$$

where $s_{j t}$ is the market share of $j$ in the population, $s_{0 t}$ is the share of the outside good and $s_{j t \mid g}$ is the within-group share of brand $j$. The unobserved product specific utility, $\xi_{j t}$, serves as the error term. It, for example, captures the effect of manufacturers' marketing that is not explicitly included in the demand (see e.g. Besanko et al., 1998; Villas-Boas and Winer, 1999; Sudhir, 2001).

\subsection{Modeling goodwill}

Firms may engage in advertising efforts to build brand equity as well as to stimulate the actual sales. We assume that advertising forms a stock variable, i. e. goodwill. Goodwill depreciates over time but can by replenished by advertising. Firm j's goodwill stock $G_{j t}$ in period $t$ is given by

$$
G_{j t}=\left(1+G R P_{j t}\right)^{1-\lambda_{j}}\left(G_{j, t-1}\right)^{\lambda_{j}}
$$

\footnotetext{
${ }^{2} \mathrm{~A} \sigma$ close to one indicates that the within group correlation of utility levels goes to one.

${ }^{3}$ Even though problems due to ignoring unobserved heterogeneity are well known, we will assume that the demand model in (2) captures the behavior of the aggregate demand sufficiently well.
} 
where $\lambda_{j}$ is the retention rate of advertising and $G R P_{j t}$ is the advertising effort of brand $j$ in $t$ measured in terms of Gross Rating Points, i. e. the percentage number of targeted viewers contacted times the average number of contacts per targeted viewer. Notice that when a firm chooses not to advertise, its goodwill depreciates. $^{4}$ A brand specific $\lambda_{j}$ controls for an overall different advertising philosophy of a firm as well as for differences in advertising quality across brands. ${ }^{5}$ We selected a Cobb-Douglas type goodwill production function for two reasons. First, it is a commonly used modeling approach for production functions and second, it allows us to develop a simple methodology to infer unobserved goodwill stocks. Notice also that the goodwill production function given in (4) can easily accommodate a multiplicative shock which randomly affects the accumulation of goodwill. However, such a shock could also be considered part of the unobserved utility component we have in the utility formulation given the way goodwill enters the utility function. A very important question is whether our concave goodwill production function in (4) - and the concave sales response function it implies - can lead to periods with no advertising. This question cannot be answered in isolation from the competitive environment firms face, thus we will come back to this point after introducing our model of firm behavior.

$G_{j t}$ is a consumer state variable that cannot directly be observed by researchers. This is a major obstacle for analyzing advertising behavior as it may directly depend on the level of goodwill. However, conditional on the model we presented above, it is possible to identify the differential impact of current advertising controlling for the changes in the other factors. That is, by simply applying a Koyck transformation on (3), we are able to identify parameters of the demand function as well as the goodwill production function. Formally, subtracting $\lambda_{j}$ times the equation in (3) at

\footnotetext{
${ }^{4}$ Notice that the mapping of the past goodwill level to the new goodwill stock has two rest points, zero and one. We assume that firms have encountered a goodwill level larger than one at one point in time in the past, therefore if a firm chooses not to advertise forever its goodwill level approaches one from above.

${ }^{5}$ The reason we restrict the replenishment rate to $1-\lambda_{j}$ is the fact that it is not separately identifiable from the impact of goodwill stock on utilities. See equation (5). Thus, the goodwill levels we infer based on these demand and production functions are unique upto a monotone transformation.
} 
$t-1$, we obtain

$$
\begin{aligned}
\ln \left(\frac{s_{j t}}{s_{0 t}}\right)-\lambda_{j} \ln \left(\frac{s_{j, t-1}}{s_{0, t-1}}\right)= & \alpha_{j}\left(1-\lambda_{j}\right)+\beta\left(p_{j t}-\lambda_{j} p_{j, t-1}\right) \\
& +\mu\left(1-\lambda_{j}\right) \ln \left(G R P_{j t}+1\right)+\sum_{k=1}^{K} \gamma_{k}\left(X_{k j t}-\lambda_{j} X_{k j, t-1}\right) \\
& +\sigma\left(\ln \left(s_{j t \mid g}\right)-\lambda \ln \left(s_{j, t-1 \mid g}\right)\right)+\xi_{j t}^{*} .
\end{aligned}
$$

with $\xi_{j t}^{*}=\xi_{j t}-\lambda \xi_{j, t-1}$. Observe equation (5) is free of the level of goodwill. It tries to explain changes in demand due to new advertising efforts, $G R P_{j t}$, controlling for the changes in other variables. Given a sufficient set of instruments, one could identify $\lambda_{j}$ and $\mu$ by an instrumental variable estimation of (5). Given $\lambda_{j}$ and sufficiently long information on GRP levels, one can reconstruct a time series of goodwill levels using (4). The initialization of $G_{j, t-1}$ in (4) may create a problem. Fortunately, we do have an additional year of advertising data prior to the period we used in the demand estimation. Thus, we are able to filter out goodwill levels which are practically free of initial condition problems.

\subsection{Modeling firms' advertising strategies}

As we have stated earlier, our main goal in this paper is to explain observed advertising strategies of firms, and gain insights on how timing and duration of ad campaigns are determined. We presume a dynamic environment where firms strategically make decisions and observed advertising choices are the equilibrium outcome of such a strategic interaction. It is well known such dynamic strategic situations may have a large number of possible equilibrium outcomes, thus we further restrict our attention to an equilibrium concept which is simple to describe and has been widely employed in the literature. That is, we adopt the Markov Perfect Equilibrium (MPE) concept which implies that firms will adopt policies which are functions of the payoff relevant states of the world in equilibrium. Our focus on MPE is not only due its popularity and wide-spread acceptance in the economics literature, but also MPE strategies are relatively simple and intuitive to describe. Firms, in equilibrium, react to the state of the nature they face.

Each firm chooses its advertising strategies in GRPs to maximize the expected 
discounted value of its current and future net cash flows. The future earnings of a firm are not only affected by its own advertising strategy but also by the strategies of its competitors. Thus, in order to make optimal advertising decisions the firm must have some perceptions on competitors' advertising strategies conditional on current information. Given that its opponents adopt Markovian policies, a simple dynamic programming argument implies also that a firm will respond to its competitors policies with a Markovian policy. That is, each firm solves a dynamic program to derive its own optimal policy, and, when such policies form best responses to each other, a MPE obtains. As mentioned before, MPE policies are functions of the payoff relevant states of the world. For now let us partition these states to three groups and at time period $t$, denote the states of the world which exogenously evolve by $\mathcal{S}_{t}$, the vector of goodwill stocks of the opponents of firm $j$ by $G_{-j, t}$, the goodwill level of firm $j$ by $G_{j, t}$ at the beginning of period $t+1$. The vector of all goodwill stocks is denoted by $G_{t}$.

To make our arguments more concretely, let the per period profit of a typical manufacturing firm, say $k$, be

$$
\Pi_{k t}\left(w_{k t}, p_{t}, G_{t-1}, G R P_{t}, \mathcal{S}_{t}\right)=\left(w_{k t}-c_{k t}\right) s_{k t}\left(G_{t-1}, G R P_{t}, p_{t}, \mathcal{S}_{t}\right)-C\left(G R P_{k t}, \mathcal{S}_{t}\right)
$$

where $w_{k t}$ is the wholesale price and controlled by the manufacturer, $p_{t}$ is the vector of retail prices controlled by the retailer and $c_{k t}$ is the constant marginal cost per unit which evolves exogenously. We also assume that the vector of unobserved components of the consumer utilities, $\xi_{t}$, exogenously evolves. The total sales of firm $k$ in period $t$ is denoted by $s_{k t}\left(G_{t-1}, G R P_{t}, p_{t}, \mathcal{S}_{t}\right)$ and is simply the nested logit market share of firm $k$ times the market size. In (6), $G_{t-1}$ denotes the vector of goodwill levels of all firms accumulated until the beginning of period of $t$, while $G R P_{t}$ denotes current advertising intensities they select. $C\left(G R P_{k t}, \mathcal{S}_{t}\right)$ is the cost of advertising incurred by firm $k$. Notice that we allow both the demand and cost functions to be affected by the vector of uncontrollable states of the world, $\mathcal{S}_{t}$. The possible elements of this vector will be further defined below. Each firm can influence its own goodwill level in the future by investing in advertising, i.e. by buying GRPs, via the goodwill production function in (4).

Before describing the dynamic decision problem faced by firms in selecting their 
advertising strategies, let us note that we are assuming the prices, both retail and wholesale, are set after advertising decisions are made and do not affect future states of the world in this setup. That is, a manufacturer, by pricing low today and therefore selling more, cannot influence its future profits by its pricing decisions. This implies that the equilibrium in retail and wholesale prices are established in a myopic manner. That is, firms maximize (6) given the data on the state of the world as well as their conjectures about the competitors actions, and hence also these prices are functions of the payoff relevant states of the world. Therefore, at the time of making an advertising decision, we could view the profit function of a firm just as a function of the state variables and advertising choices, i.e.

$$
\Pi_{j t}\left(G_{t-1}, G R P_{t}, \mathcal{S}_{t}\right)=\Pi_{j t}\left(G_{j, t-1}, G_{-j, t-1}, G R P_{t}, \mathcal{S}_{t}\right)=\Pi_{k t}\left(\bar{w}_{k t}, \bar{p}_{t}, G_{t-1}, G R P_{t}, \mathcal{S}_{t}\right)
$$

with $\bar{w}_{k t}=w_{k t}\left(G_{t-1}, G R P_{t}, \mathcal{S}_{t}\right)$ and $\bar{p}_{t}=p_{t}\left(G_{t-1}, G R P_{t}, \mathcal{S}_{t}\right)$.

The only controllable state is the goodwill carried over to tomorrow, that is by investing in higher GRP levels today, a firm can increase its goodwill stock at the beginning of the next period. Thus, each firm has one control variable, $G R P_{k t}$. The other payoff relevant state variables are e.g. marketing-mix variables such as display and feature which are presumably controlled by the retailers, CPMs (cost per thousand viewers), production costs which effects per unit profitability, etc. Even the vector of unobserved product characteristics, $\xi_{t}$, could be viewed as part of the state since they are known to the firms. These variables are assumed to evolve exogenously and are included in $\mathcal{S}_{t}$.

In a MPE, firm $j$ takes the policies $G R P_{k t}\left(G_{t-1}, \mathcal{S}_{t}\right), \quad k \neq j$ of all the other firms, and the goodwill production function in (4) and solves the following dynamic program

$$
\begin{aligned}
\left\{V_{j}\left(G_{t-1}, \mathcal{S}_{t}\right)=\right\} \max _{G R P_{j t} \geq 0} & \Pi_{j t}\left(G_{t-1}, G R P_{j t}, \mathcal{S}_{t}\right)-C\left(G R P_{j t}, \mathcal{S}_{t}\right) \\
& +\psi E\left[V_{j}\left(G_{t}, \mathcal{S}_{t+1}\right) \mid \mathcal{S}_{t}, G R P_{t}\right]
\end{aligned}
$$

such that (4) holds. At the optimal policy of firm $j$, the equality in the curly brackets is satisfied, defining recursively the value function, $V_{j}(\cdot, \cdot)$. This formulation does not allow firms to decide to start a campaign or end it. If the cost function $C\left(G R P_{j t}, \mathcal{S}_{t}\right)$ has fixed components when a firm starts a campaign, appropriate 
control variables for starting and ending a campaign as well as state variables discriminating a campaign period from a no advertising period could be included in the model as suggested in Hahn and Hyun (1991). Even though we imagine the competitive environment firms operate in implies such fixed costs, we do not include these components for the sake of simplicity in this exposition. However, it should be noted that we do not outrule such fixed costs affecting the form of MPE policies that we study below. Furthermore, in (7), we have not explicitly stated an upper bound on GRPs each firm can contract in a given period. Given the limited number of advertising slots, such a constraint would also play an important role in shaping the advertising strategies of firms. Keeping these caveats in mind, we assume that each firm decides how much to advertise if at all every period after observing the state of the world. In this setting, a policy function of the form $G R P_{j t}\left(G_{t-1}, \mathcal{S}_{t}\right)$ for each firm $j$ will form a MPE.

Unfortunately, deriving advertising policies $G R P_{j t}\left(G_{t-1}, \mathcal{S}_{t}\right)$ analytically is impossible in the simple setup we described above. In fact, this is the very reason Dube et al. (2003) and Doraszelski and Markovich (2004) employ numerical methods to derive and describe the shape of advertising policy functions. In this paper, we will instead assume that firms' observed advertising activities are the result of a MPE. Note that, this is the only restriction we place on the strategic interaction. We, then, use the information we have on the characteristics of a MPE to investigate determinants of advertising activity in reduced form. The restriction to MPE suggests that firms will adopt policies of the form $G R P_{j t}^{*}=G R P_{j t}\left(G_{t-1}, \mathcal{S}_{t}\right)$ where for some states of the world $G R P_{j t}^{*}=0$ will be the implied action. We approximate the optimal policy as

$$
G R P_{j t}\left(G_{t-1}, \mathcal{S}_{t}\right)= \begin{cases}f\left(G_{t-1}, \mathcal{S}_{t}\right)+\eta_{j t}, & f\left(G_{t-1}, \mathcal{S}_{t}\right)+\eta_{j t}>0 \\ 0, & f\left(G_{t-1}, \mathcal{S}_{t}\right)+\eta_{j t} \leq 0\end{cases}
$$

where the approximation error, $\eta_{j t}$, is assumed to be normal and use (8) in tobit regressions with a variety of specifications of the function $f$ and uncontrollable states, $\mathcal{S}_{t}$, to describe the observed advertising policies in section 4 . 


\subsection{Discussion}

In this subsection, we would like to first summarize our approach. We start with assuming that advertising increases the value of a brand via a goodwill stock. We, then, introduce a demand specification including goodwill as a demand shifter. In the absence of advertising the goodwill stock depreciates, and can be replenished by advertising. Thus, we also specify a goodwill production function which describes the dynamic evolution of the goodwill stock. Based on these specifications, we formulate an estimation strategy for the model parameters. Given parameters and sufficiently long data on advertising, we can reconstruct the unobserved goodwill stock of firms by using the production function.

We, then, briefly introduce a competitive environment to motivate our focus on MPE advertising strategies which depend on payoff relevant states of the nature. An important set of state variables are the unobservable goodwill stocks of firms which we can indirectly infer via our first stage analysis. We do not fully specify a dynamic game which generates the observed advertising in equilibrium as in DHM. Instead, we use the implications of the MPE, and explore reduced form relationships between observed advertising behavior and payoff relevant state variables including goodwill stocks.

An important question at this juncture is whether our concave response function can yield advertising choices similar to those observed in the data, especially, given the fact that there exists a number of papers that argue that pulsing is only possible in the presence of an S-shape advertising response function (see e.g. Sasieni, 1971; Mahajan and Muller, 1986). Though we do not focus on pulsing, the questions remains whether a firm would ever stop advertising or adopt a non-uniform advertising strategy in the presence of a globally concave sales response function. First, as DHM note, there is no established result that implies globally concave response functions under competition do not yield to pulsing. Second, Hahn and Hyun (1991) show that firms may stop advertising even in the presence of a concave response function if their cost function contained fixed cost components. Given that we have not fully specified the underlying dynamic game, our setup certainly allows such fixed components of advertising costs. 
A brief inspection of (6) points out several other instances where firms may pick zero advertising. For example, a high positive shock which increases the production cost reduces $c_{j t}$ which in turn reduces the marginal profitability of advertising. In certain states of the nature this would induce firms to not advertise. Another source of variation in advertising policy in our model may simply be due to the variation in the marginal cost of advertising. In fact, the cost of advertising (measured by the cost to contact thousand people) exhibits seasonality with high variation in our dataset. In our reduced form models we try to control for each of these factors in addition to goodwill.

In closing this subsection, we would like to relate our approach to that of DHM and highlight where we differ. As outlined above, our paper is in some aspects very similar in its modeling approach to DHM. Both start by estimating the parameters of a goodwill production and advertising response function using a demand specification and both adopt logit based discrete choice models. We use a somewhat simpler goodwill and sales response function which differ significantly from that of DHM. The most crucial difference is that DHM employ a threshold response model while we use a globally concave one. Even though it is possible to incorporate a threshold response function in our approach ${ }^{6}$, our dataset does not allow us to pursue this avenue.

Our modeling approach is significantly different from DHM in the second stage of analysis. DHM use the estimated parameters to numerically compute the Markov perfect equilibrium of a particular advertising game that they specify using an algorithm similar to that of Pakes and McGuire (1994). We, on the other hand, sketch

\footnotetext{
${ }^{6} \mathrm{DHM}$ demonstrate that pulsing will occur with a threshold sales response function model. Incorporating a threshold in our model is trivial

$$
G_{j t}= \begin{cases}\left(1+G R P_{j t}-T\right)^{1-\lambda_{j}}\left(G_{j, t-1}\right)^{\lambda_{j}}, & G R P_{j t} \geq T \\ \left(G_{j, t-1}\right)^{\lambda_{j}} & \text { otherwise }\end{cases}
$$

with $T$ denoting the threshold value. In principle, our approach — which estimates the parameter $\lambda$ by means of a Koyck transformation on the demand side estimating equation - can be extended to accommodate the estimation of the threshold level $T$ also. However, our data does not contain sufficiently many observations with low non-zero levels of advertising complicating the identification of such a threshold.
} 
the main ingredients of a dynamic game to motivate our use of Markovian policies in a reduced form analysis. Furthermore our approach allows us to identify payoff relevant state variables. We do not fully specify a dynamic game and solve it as DHM do. Instead, we investigate the relationship between observed advertisingassuming they constitute a MPE of some game - and payoff relevant state variables in order to determine stylized features of advertising policies.

Our reduced form analysis, in the next section, clearly indicates a direction where firms make advertising scheduling as well as campaigning decisions. DHM on the other hand impose a particular strategic environment to derive equilibrium advertising policies. Even though their equilibrium advertising policies exhibit pulsing they are not similar in nature to the observed advertising policies at all. This could be due to two reasons. Either the firms do not behave as they should or DHM fail to account for important features of strategic interaction between the firms in their model. Hence, our contribution is complementary to those of DHM and could be viewed as a vital input to a research strategy as theirs. We try to establish stylized facts about observed advertising policies conditional on a MPE specification. Thus, our results should help in formulating a dynamic game where the observed advertising patterns can arise as equilibrium outcomes.

\section{An empirical study of dynamic advertising com- petition}

\subsection{The data}

We take the model introduced in Section 2 to a national store-level scanner panel dataset on the category of liquid detergents. The dataset covers 156 weeks from January 1998 to December 2000, consists information on 175 stores and is provided by IRI, Germany. This market is dominated by four manufacturers who represent more than 96 percent of the market. Private label sales as well as the sales of a few generic brands are marginal. We therefore restrict our analysis to these four brands.

Each manufacturer offers a variety of horizontally differentiated products. Articles of one manufacturer belong to a brand. Advertising is primarily done in TV 
and advertising corresponds to brands not articles. All variants of a brand are sold in $750 \mathrm{ml}$ bottles and prices across variants of a brand are typically identical. We are not allowed to expose brand names so that we label them as A, B, C and D. Among these four, brand $\mathrm{B}$ is the dominant one with roughly $35 \%$ market share, followed by brand $\mathrm{D}$ at $25 \%$, brand $\mathrm{A}$ at $22 \%$ and brand $\mathrm{C}$ at $18 \%$. The largest three of these four brands - A, B and D-advertise on TV. The four brands are sold at average prices of $3.24(\mathrm{~A}), 4.06(\mathrm{~B}), 3.25(\mathrm{C})$ and $3.21(\mathrm{D}) \mathrm{DM}^{7}$ As it is typical for consumer goods, display and feature activities are used to promote the sales of the brands. In Table 1, we provide some descriptive statistics of these brands where $\mathrm{SD}, s_{i}$ and $s_{i \mid g}$ denote the standard deviation of the respective variable, the market share in the population and the market share within the liquid detergent market, respectively.

We aggregated the data from the 175 stores to create a representation of the German market. We acknowledge the fact that this may introduce some problems for parameter estimation. However, TV advertisement data are reported for the marketlevel, i.e. the total German market. In addition, consumer goods manufacturers usually do not try to target regional sub-markets through TV advertisements in Germany. This would be an ineffective strategy, as those TV stations that allow for local advertisements usually cover only very small fractions of the total market. Moreover, in Germany most TV advertisements are sold by two large media agencies which have contracts with the large national (market-level) TV stations.

To implement a nested logit demand, we need to know the market size so that we can compute market shares. In order to compute a market size corresponding to our aggregate dataset, we collected data from GfK and "LZ Lebensmittelreport" about the distribution of retail formats and the shopping behavior of households in these formats. Using this information, we determine a market size corresponding to our representative market. Furthermore, we may face some inconsistencies in the store basis - a typical problem in using scanner panel data. To account for the potential influences of the changes in the store base, we introduce brand specific constants for each year.

\footnotetext{
${ }^{7}$ For the period of our study, the currency unit was German Marks (DM). In our analysis, we remain with the older unit and do not convert prices to Euros.
} 
Table 1: Descriptive Statistics

\begin{tabular}{l|cc|cc|cc|ccc|cc|cc}
\hline \hline \multirow{2}{*}{ Brand } & \multicolumn{2}{|c|}{$s_{i \mid g}$} & \multicolumn{2}{|c|}{$s_{i}$} & \multicolumn{2}{c|}{ Price } & \multicolumn{2}{c|}{ GRP } & \multicolumn{2}{c|}{ Display } & \multicolumn{2}{c}{ Feature } \\
& Mean & SD & Mean & SD & Mean & SD & Mean & SD & Mean & SD & Mean & SD \\
\hline \hline A & 21.72 & 2.60 & 3.35 & 0.75 & 3.24 & 0.20 & 10.45 & 29.49 & 0.30 & 0.19 & 0.32 & 0.17 \\
B & 33.31 & 3.98 & 3.82 & 0.83 & 4.06 & 0.28 & 39.49 & 37.05 & 0.24 & 0.15 & 0.24 & 0.14 \\
C & 17.95 & 2.31 & 1.96 & 0.85 & 3.25 & 0.20 & 0 & 0 & 0.26 & 0.18 & 0.29 & 0.16 \\
D & 25.02 & 2.97 & 2.71 & 0.79 & 3.21 & 0.20 & 32.97 & 39.62 & 0.28 & 0.20 & 0.30 & 0.17 \\
\hline \hline
\end{tabular}

The advertising data consists of gross rating points (GRPs), representing a reach times frequency measure within households in Germany. Reach is the fraction of households that have been exposed to an ad at least one time in that week. Frequency is a measure of the average number of times a household, given that it was reached, has had contact with the ad. GRPs offer the advantage over budgets that they are closer to the real decisions of marketing managers. They usually decide on GRPs and the budget is realized ones a media agency has made the plan how to meet the required GRP level. We do have an additional year of data on advertising prior to the period we use in our analysis. Figure 1 provides the GRP levels of each brand for a period of 207 weeks for which we have advertising data. Hence, the additional year of GRP realizations for brands B and D are also presented in Figure 1.

We observe very low GRP values for a few periods. These are typically the periods at the end of a campaign where the media agency had to book some TV advertising slots to realize the GRP target. DHM refer to this practice as "making goods" and points out the importance of such observations in identifying a threshold value for the sales response function. In our dataset observations which can be classified as "making goods" are relatively scarce compared to the data of DHM. This is one reason why we do not attempt to estimate a threshold response model.

State variables we have are goodwill levels carried over from the previous period, demand shifters which are observed prior to the advertising decision, per unit production costs, and the advertising costs. We operationalize advertising cost by using the price to contact a thousand viewers (CPMs) from a target group. This measure 

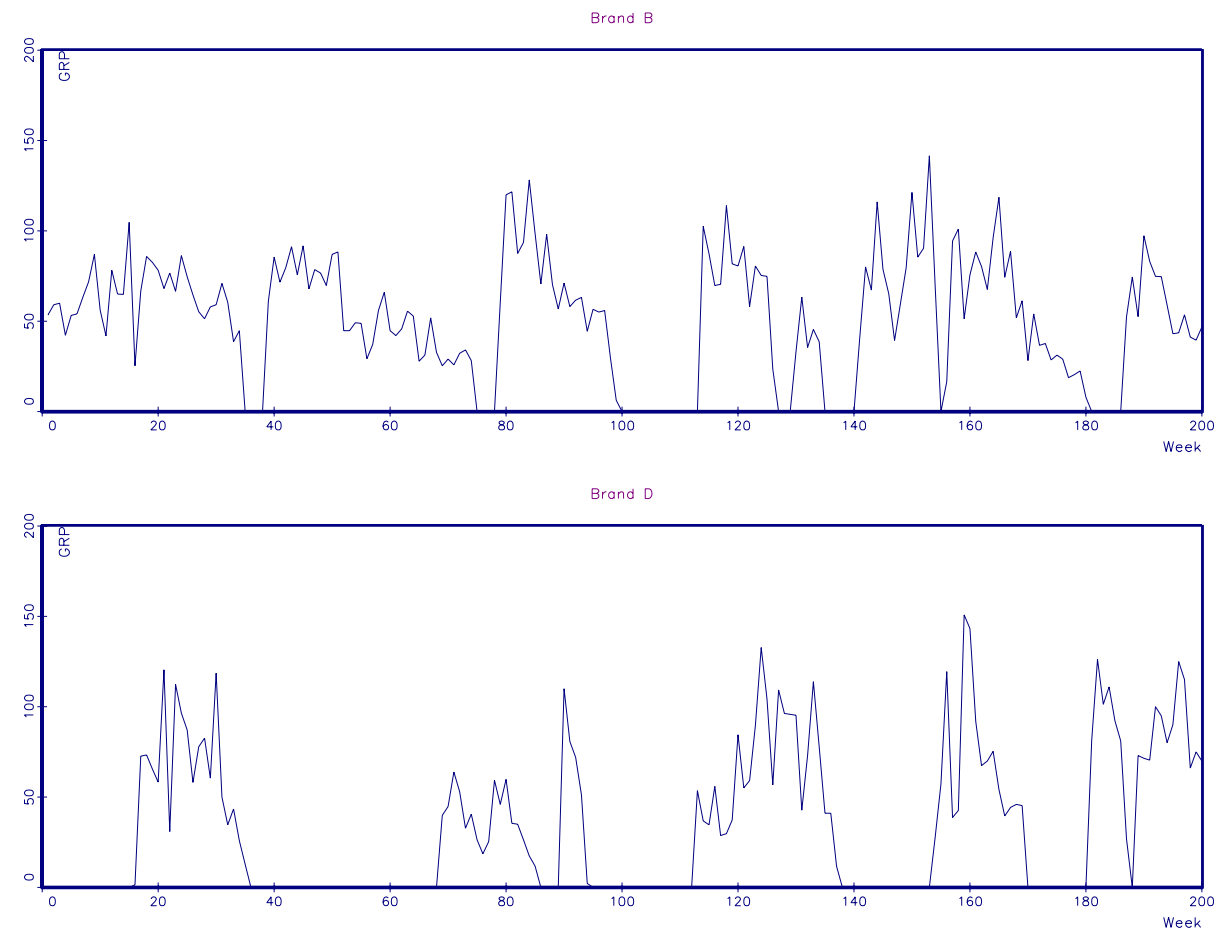

Figure 1: GRPs of Brand B and D across 4 years

is used by manufacturers to estimate gross costs of an advertising campaign. In addition, the prices to reach a thousand viewers are readily available for each period and they are classified for different advertising media, e.g. TV versus print as well as for different TV stations. It is important to note that the costs of advertising vary substantially across time and hence these costs may affect firms advertising choices.

Firms' advertising choices may also depend on production costs which are not provided in the data. Hence, we adopt a modeling strategy to infer wholesale prices and costs from the data following ideas from the empirical industrial organization literature (e.g. Bresnahan, 1989; Berry, 1994; Sudhir, 2001). We model the retailer-manufacturer channel interaction as a manufacturer Stackelberg game within a structural model of demand and supply. For a more detailed discussion on how we infer the per unit production costs, see Klapper and Doganoglu (2004). We also use (3) to compute the unobserved product specific utility, $\xi_{j t}$, which we then employ in some specifications of the reduced form analysis as a state variable. 


\subsection{Demand estimates}

In this subsection, we present the results of the nested logit demand estimation based on (5). The specification of the group level utility function in (2) needs to be stated more precisely. As mentioned above, we do include brand specific yearly constants to account for possible heterogeneity in our data. Prices and promotional activities are highly related. Especially in those weeks in which retailers temporarily reduce the price of a brand and simultaneously engage in display activities and featuring, consumers may respond differently to prices. To account for this fact we do include an interaction effect of price and the sum of display and feature advertising into the mean utility function. Log of goodwill enters the mean utility function as outlined in (5). We assume a common $\mu$ across brands. The retention rate $\lambda_{j}$ is brand specific, hence we assume that each brand has its own potential to build goodwill. We control for first order autocorrelation when we estimate (5). We additionally tested for second or higher order autocorrelation but did not find evidence of higher than first order autocorrelation.

As has been outlined in many papers (e.g. Villas-Boas and Winer, 1999; Besanko et al., 1998) manufacturers have information on consumer response to price and advertising that are not contained in our data. This leads to the well known endogeneity problem because the demand error $\xi_{j t}^{*}$ is correlated with price and advertising. We apply an instrumental variable estimation technique, i.e. a Generalized Method of Moments (GMM)-estimator. We additionally tested for endogeneity of display and feature advertising applying the usual modified Hausman test (Hausman, 1978). We cannot reject the hypothesis of exogeneity of display and feature advertising. Hence we make use of these two variables as instruments for prices. We further collected detailed information about costs in our liquid detergent category. The main cost drivers are related to the raw materials and packaging. In addition, firms have to pay an extra fee that is related to the environmental suitability of the package. We got precise brand specific information regarding these three cost drivers and included them into the instrumental variable list.

To instrument for advertising in the demand equations we used two cost measures, i.e. the cost per thousand viewers and the price per 30 seconds. We use the 
Table 2: Demand parameter estimates

\begin{tabular}{c|cc}
\hline Parameter & Estimate & App Std Err \\
\hline \hline$\alpha_{A_{1998}}$ & -1.72954 & 0.2584 \\
$\alpha_{B_{1998}}$ & -1.01771 & 0.3065 \\
$\alpha_{C_{1998}}$ & -1.92718 & 0.2925 \\
$\alpha_{D_{1998}}$ & -1.64287 & 0.2521 \\
$\alpha_{A_{1999}}$ & -1.95771 & 0.2434 \\
$\alpha_{B_{1999}}$ & -1.22551 & 0.2927 \\
$\alpha_{C_{1999}}$ & -1.90029 & 0.2506 \\
$\alpha_{D_{1999}}$ & -1.97090 & 0.2368 \\
$\alpha_{A_{2000}}$ & -1.83071 & 0.2512 \\
$\alpha_{B_{2000}}$ & -0.89666 & 0.3136 \\
$\alpha_{C_{2000}}$ & -1.66966 & 0.2740 \\
$\alpha_{D_{2000}}$ & -1.92651 & 0.2660 \\
$\sigma$ & 0.23586 & 0.0321 \\
$\beta_{\text {Price }}$ & -0.51449 & 0.0701 \\
$\beta_{\text {PricePromotion }}$ & -0.21033 & 0.0400 \\
$\gamma_{\text {Display }}$ & 0.64154 & 0.1497 \\
$\gamma_{\text {Feature }}$ & 1.17890 & 0.1242 \\
$\mu$ & 0.06448 & 0.0167 \\
$\lambda_{A}$ & 0.70083 & 0.0956 \\
$\lambda_{B}$ & 0.87176 & 0.0894 \\
$\lambda_{D}$ & 0.90225 & 0.0348 \\
\hline & & \\
\hline
\end{tabular}

mean values of these cost measure across those TV stations that brands A, B and D used for their TV campaigns therefore they are brand specific. We additionally tested the appropriateness of lagged GRP-levels as instruments. However the inclusion of the lagged GRP-levels did not change the demand estimates. We have more instruments than endogeneous variables within each equation and therefore tested the hypothesis that the over-identifying restrictions are valid. This hypothesis cannot be rejected. 
The GMM-parameter estimates based on this list of instrumental variable are shown in Table 2. We will only briefly comment on these estimates. Most of them are significant. Brand constants for each year show that the market leader (brand B) possesses the highest intrinsic brand preference. The three other brands are valued more closely but the ordering of the brand constants within years changes. However, the brand constants are still related to within group market shares. In particular, the within group share of brand C raised from 14.6 percent in 1998 to 20.5 percent in 2000. On the contrary the within group market share of brand A declined from 23.3 percent in 1998 to 20.2 percent in 2000 and that of brand B from 37.5 percent in 1998 to 34.3 in 2000 . The within group market share of brand D increased from 24.6 percent in 1998 to 26.1 percent in 1999 and then declined again to 24.2 percent in 2000 . Thus these yearly within group market share variations are also reflected in the brand specific yearly constants. Hence our estimates of constant brand preference seem to be face valid.

Two parameters, $\beta_{\text {Price }}$ and $\beta_{\text {PricePromotion, are related to price. They imply mean }}$ price elasticities of -2.53 for $\mathrm{A},-2.89$ for $\mathrm{B},-2.52$ for $\mathrm{C}$ and -2.45 for D. These elasticity estimates are plausible and realistic for the liquid detergent market. Promotions, i.e. display and featuring, significantly increase the utility and consequently the market shares. The estimated correlation across tastes for brands, $(\sigma)$, is 0.235 which suggests a moderate degree of the within group correlation of utility levels.

The main parameters of interest are those related to advertising. We assumed a common response of our consumers to current advertising exposure levels. This effect is positive and significant and implies average advertising elasticities of 0.0786 for A, 0.0796 for B and 0.0777 for D. These elasticities are very small but they only reflect the direct weekly effect of advertising. The retention rate is estimated at the brand level for those brands that advert, i.e. brands A, B and D. We get an estimate of 0.701 for A, 0.871 for B and of 0.902 for D. Brand A advertises only 23 of 156 weeks in the sample we used for estimation. In the remainder of the paper, we will not investigate the advertising strategies of brand A due to the lack of sufficient advertising observations. In order to verify that the estimated retention rates of $\mathrm{B}$ and $\mathrm{D}$ are not biased due to the inclusion of brand $\mathrm{A}$ in the estimation, we additionally estimated the demand system where we restricted $\lambda_{A}$ to zero. This 
analysis yields a $\lambda_{B}$ of 0.861 and a $\lambda_{D}$ of 0.910 . The very small differences to those values in Table 2 are statistically not significant.

\subsection{Analyzing dynamic advertising competition}

\section{Inferring goodwill}

We now use the estimated retention rate to infer goodwill from our goodwill production function in (4). Notice that (4) recursively determines the current goodwill stock, thus the recursion should be initialized. Fortunately, we do have 52 additional weeks of GRP choices prior to our estimation sample which we use to run (4). Thus, the effect of the initialization diminishes almost completely throughout these 52 weeks. Figure 2 shows the implied goodwill stocks for B and D as well as the observed GRP choices of the two brands. Once again, the implied goodwill stocks are presented for the entire period of four years for which we have information on GRP choices, even though the estimates of $\lambda$ are based only on the last three years. This figure nicely illustrates how the two brands can build up goodwill and how it declines when firms stop advertising. Note that this behavior is by design. However, also note that the goodwill levels where a firm stops advertising and starts campaigning again are surprisingly similar across time for both firms. This however is not a simple artifact of using (4) and is implied by the observed advertising data.

\section{Accounting for campaigning}

A brief inspection of Figure 2 reveals that firms advertise when their goodwill is low and they stop advertising after a threshold level is reached. Advertising starts again, once goodwill depreciates below a lower threshold. This suggests that firms may be employing $(\mathrm{S}, \mathrm{s})$ type policies. That is, as long as goodwill is above s, they do not advertise. Once goodwill falls below s, they start a campaign, which runs until goodwill is brought up to S. Thus, firms may have an additional decision variable: campaign or not. With an $(\mathrm{S}, \mathrm{s})$ type strategy, a firm will advertise at goodwill stock $\bar{G}, s<\bar{G}<S$, if it is campaigning, while at the same level of goodwill stock it will remain idle if it is not campaigning. Firms could easily update a state variable related to campaigning based on their current decisions. This variable is also payoff 

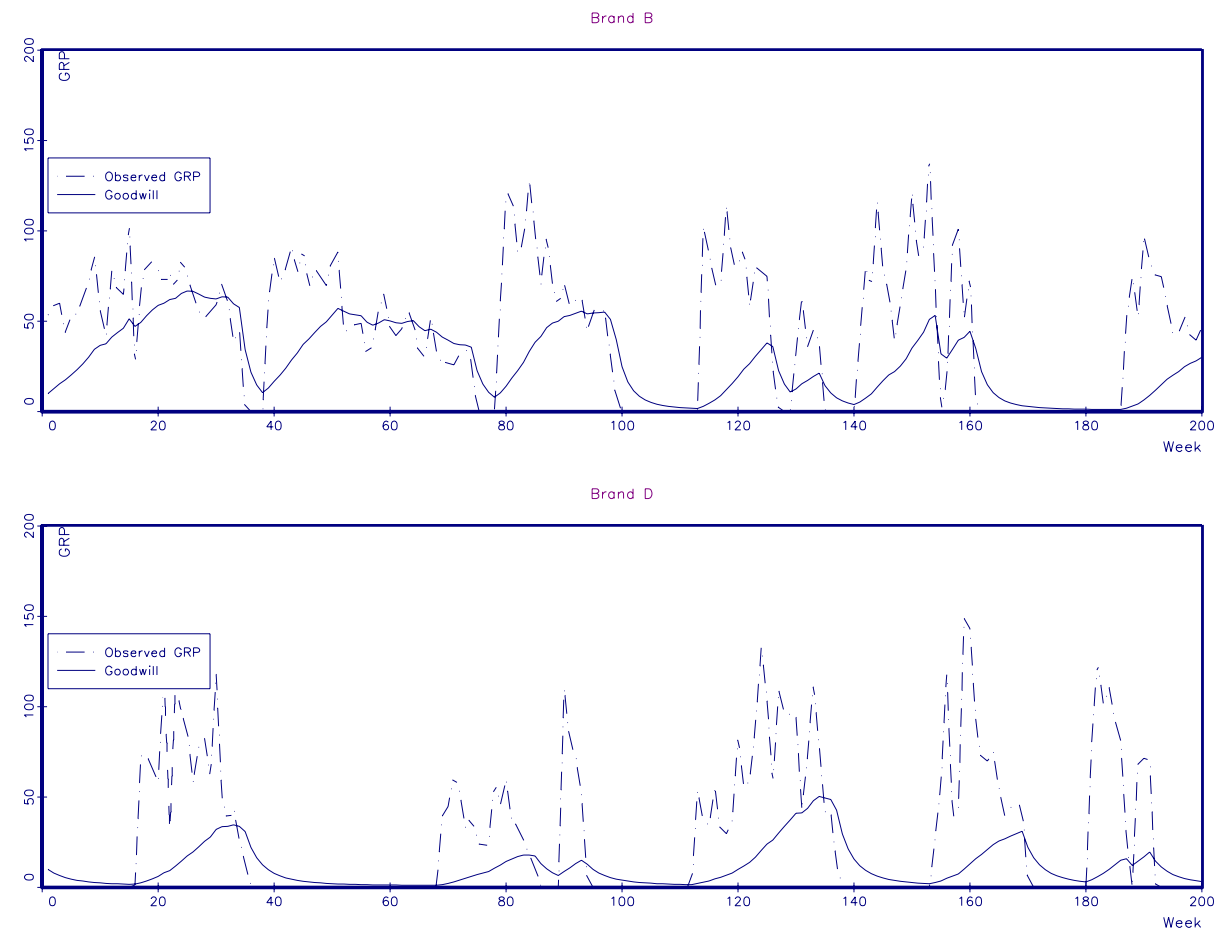

Figure 2: GPP-levels and inferred goodwill of Brand B and D across 4 years

relevant since when it is zero firms may have to consider incurring a fixed cost in case they advertise.

Unfortunately, we do not have explicit information on whether a firm is in a campaign or not. Since we do not have explicit information on whether and when firms campaign, we will attempt to approximate this variable. If the goodwill is increasing from a period to another, this implies that the firm has advertised in the past period with a goal of increasing its goodwill which in turn suggests that a firm might be campaigning. Thus, our approximation records whether a firm is campaigning or not by an indicator of positive changes in goodwill stock. Let $C I_{j}(t)$ denote an indicator - a state variable - which is one when the goodwill level of a firm has increased in the previous period, then

$$
C I_{j}(t) \cong\left\{\begin{array}{lc}
1, & G_{j, t-1}-G_{j, t-2}>0 \\
0, & \text { otherwise }
\end{array}\right.
$$

Clearly, this approximation contains information from two periods before, thus it is not in the spirit of an MPE. Nevertheless, this is only our implementation of 
this variable, while firms do not need information from earlier periods to determine whether they are in a campaign or not, they do know it. We will also use the goodwill level of a firm whenever $C I_{j}(t)=1$ to account for the impact of current goodwill level on advertising intensity.

\section{Other factors}

During the three years that we analyze the competitive landscape experienced a few changes. For example in the first year of our analysis, i.e. in 1998, a third firm,

brand $\mathrm{A}$, has advertised as well for a brief time period, while in the remaining years they chose not to use TV advertising in their marketing mix. Both firm B and D, potentially reacted to advertising by brand A. In order to control for such reactions, we use a dummy variable which is one during 1998. Furthermore, in 2000, last year of our analysis, both brands B and D have introduced new products in a related category. Thus, both firms might have adjusted their advertising policy in the liquid detergents category due to their efforts in promoting the new products. We use another dummy variable which is one during 2000 to control for such shifts in the advertising policies of both firms.

\section{Estimated models}

We estimated tobit models with various specifications. They differed in many aspects, e.g. the number of state variables included and the degree of nonlinearities. We provide some of the empirical findings for brand B and brand D which show regularities in some important aspects. Table 3 presents which of the aforementioned variables have been included in various tobit models that we have estimated. Recall that $C P M_{j t}$ is the cost per thousand for brand $j$ of those $\mathrm{TV}$-stations that it selects, $c_{j t}$ is the marginal production cost, and $\xi_{j t}$ is the unobserved product characteristic of brand $j$. In models 1 to $6 C P M_{j t}$ enters linearly. We also tested the appropriateness of polynomial extensions of this variable in the tobit estimations. Their inclusion did not improve the fit. We also use the goodwill level of a competitor, $G_{j^{\prime}, t-1}$ as possible predictor in the tobit estimation.

\section{Explaining the dynamic advertising strategy of firm B}


Table 3: Variables included in our tobit estimation models

\begin{tabular}{|c|c|c|c|c|}
\hline Model & Included variable & & & \\
\hline 1 & $C P M_{j t}$ & & & \\
\hline 2 & $C P M_{j t} \quad C I_{j}(t)$ & & & \\
\hline 3 & $C P M_{j t} \quad C I_{j}(t)$ & $C I_{j}(t) G_{j, t-1}$ & & \\
\hline 4 & $C P M_{j t} \quad C I_{j}(t)$ & & $G_{j^{\prime}, t-1}$ & \\
\hline 5 & $C P M_{j t} \quad C I_{j}(t)$ & $C I_{j}(t) G_{j, t-1}$ & $G_{j^{\prime}, t-1}$ & \\
\hline 6 & $C P M_{j t} \quad C I_{j}(t)$ & $C I_{j}(t) G_{j, t-1}$ & $G_{j^{\prime}, t-1} \quad \xi_{j t} \quad c_{j t}$ & \\
\hline 7 & & & & $G_{j, t-1}$ \\
\hline 8 & & & & $G_{j, t-1} \quad G_{j, t-1}^{2}$ \\
\hline
\end{tabular}

Table 4 presents the estimation results for brand B for the 8 different models outlined above. We provide the parameter estimates, their standard errors in parenthesis, the loglikelihood of each model and the corresponding BIC. The estimation results show that some models perform very poorly, especially models 7 and 8 , which only contain goodwill and the squared goodwill. Thus, as clear from these two models, the sole inclusion of goodwill is not sufficient to explain the dynamic advertising behavior. We can verify from the parameter estimates of the models 1 to 6 that $C I_{j}(t)$, the campaign indicator, the goodwill level, the cost of advertising and the goodwill of competitor D are significant state variables for explaining B's advertising behavior. Apart from that, the parameter estimates of model 6 show that the additional inclusion of the unobserved product characteristics $\xi_{j t}$ or the marginal production costs $c_{j t}$ may improve the overall fit measures but then estimates are far from having any significant impact. We have verified these conclusions for numerous other models which we do not report here.

Based on the BIC criterion we do favor model 5. It provides a good fit of the included state variables to the observed GRP levels of brand B with only a limited number of covariates. Thus in our subsequent analysis, we focus on the parameter estimates of model 5 which offer some insights to the dynamic advertising behavior of brand $\mathrm{B}$.

The positive coefficient estimated for $C I_{j}(t)$ together with the negative estimate 
Table 4: Estimation results of the tobit models for brand B

\begin{tabular}{|c|c|c|c|c|c|c|c|c|}
\hline variable & Model 1 & Model 2 & Model 3 & Model 4 & Model 5 & Model 6 & Model 7 & Model 8 \\
\hline intercept & $\begin{array}{c}7.8554 \\
(26.8469)\end{array}$ & $\begin{array}{c}12.3207 \\
(20.7548)\end{array}$ & $\begin{array}{c}-2.3469 \\
(19.7932)\end{array}$ & $\begin{array}{c}51.0915 \\
(23.7316)\end{array}$ & $\begin{array}{c}40.4338 \\
(22.0502)\end{array}$ & $\begin{array}{c}43.9920 \\
(26.4728)\end{array}$ & $\begin{array}{l}18.6257 \\
(9.6580)\end{array}$ & $\begin{array}{c}-1.7558 \\
(12.3712)\end{array}$ \\
\hline$C P M_{j t}$ & $\begin{array}{c}1.5642 \\
(1.4355)\end{array}$ & $\begin{array}{l}-1.1514 \\
(1.1326)\end{array}$ & $\begin{array}{l}-0.6227 \\
(1.0582)\end{array}$ & $\begin{array}{l}-2.5199 \\
(1.2151)\end{array}$ & $\begin{array}{l}-2.1597 \\
(1.1228)\end{array}$ & $\begin{array}{l}-2.2790 \\
(1.1507)\end{array}$ & & \\
\hline$C I_{j}(t)$ & & $\begin{array}{l}72.3040 \\
(7.3866)\end{array}$ & $\begin{array}{c}108.6177 \\
(10.9671)\end{array}$ & $\begin{array}{l}74.9131 \\
(7.4666)\end{array}$ & $\begin{array}{l}112.3399 \\
(10.8456)\end{array}$ & $\begin{array}{l}111.2294 \\
(11.0159)\end{array}$ & & \\
\hline$C I_{j}(t) G_{j, t-1}$ & & & $\begin{array}{l}-1.2669 \\
(0.2754)\end{array}$ & & $\begin{array}{l}-1.3085 \\
(0.2637)\end{array}$ & $\begin{array}{l}-1.2838 \\
(0.2671)\end{array}$ & & \\
\hline$G_{j^{\prime}, t-1}$ & & & & $\begin{array}{l}-1.0987 \\
(0.3539)\end{array}$ & $\begin{array}{l}-1.1777 \\
(0.3331)\end{array}$ & $\begin{array}{l}-1.1597 \\
(0.3384)\end{array}$ & & \\
\hline$\xi_{j t}$ & & & & & & $\begin{array}{l}-12.5196 \\
(21.2172)\end{array}$ & & \\
\hline$c_{j t}$ & & & & & & $\begin{array}{c}-1.6407 \\
(12.2073)\end{array}$ & & \\
\hline$G_{j, t-1}$ & & & & & & & $\begin{array}{c}0.9782 \\
(0.3198)\end{array}$ & $\begin{array}{c}3.5164 \\
(0.9866)\end{array}$ \\
\hline$G_{j, t-1}^{2}$ & & & & & & & & $\begin{array}{l}-0.0491 \\
(0.0178)\end{array}$ \\
\hline$D^{1998}$ & $\begin{array}{c}10.4193 \\
(12.1668)\end{array}$ & $\begin{array}{l}12.1494 \\
(9.2032)\end{array}$ & $\begin{array}{l}27.5855 \\
(9.3599)\end{array}$ & $\begin{array}{l}-2.3224 \\
(9.8872)\end{array}$ & $\begin{array}{c}12.9871 \\
(9.6107)\end{array}$ & $\begin{array}{c}13.2628 \\
(10.1534)\end{array}$ & $\begin{array}{l}-18.5973 \\
(12.7584)\end{array}$ & $\begin{array}{c}-9.7520 \\
(12.7479)\end{array}$ \\
\hline$D^{2000}$ & $\begin{array}{l}-32.6411 \\
(11.1976) \\
\end{array}$ & $\begin{array}{r}-18.7161 \\
(8.5538) \\
\end{array}$ & $\begin{array}{r}-16.3801 \\
(7.9767) \\
\end{array}$ & $\begin{array}{r}-21.6088 \\
(8.4525) \\
\end{array}$ & $\begin{array}{r}-19.4318 \\
(7.7766) \\
\end{array}$ & $\begin{array}{r}-19.0858 \\
(8.4596) \\
\end{array}$ & $\begin{array}{l}-29.4021 \\
(11.1274) \\
\end{array}$ & $\begin{array}{l}-27.1442 \\
(10.9419) \\
\end{array}$ \\
\hline$\overline{\mathrm{LL}}$ & -578.539 & -532.723 & -517.747 & -522.794 & -511.234 & -511.047 & -563.402 & -565.592 \\
\hline $\mathrm{BIC}$ & 1177.226 & 1090.631 & 1065.716 & 1075.810 & 1057.727 & 1067.427 & 1146.952 & 1156.369 \\
\hline
\end{tabular}

Standard errors of the parameters are given in parenthesis

for the coefficient of current goodwill level in a campaign, suggest that firm B may be trying to reach a "target goodwill" level, and reduce its advertising intensity as this target becomes nearer. Thus firm B advertises heavily in the beginning of a campaign. This property of the estimated advertising strategy of B is consistent with its behavior as seen in the top panel of Figure 2. A firm during a campaign prefers to advertise at a relatively high level until the target is reached at which point it stops advertising. Notice the jumps in the observed advertising behavior of firm B in Figure 2. Towards the end of a campaign, the terms involving $C I_{j}(t)$ and $G_{j, t-1}$ have a combined effect which approaches zero implying a reduction in the selected GRP of firm B, thus at one point where costs of advertising is sufficiently high, being in a campaign does not warrant further advertising, and the firm may 
stop advertising abruptly. Hence, the choices of firm B are also affected by the costs of advertising in an intuitive manner. Increasing costs lower the GRP units B would pick. Extensive preliminary studies have also shown that this effect is indeed linear.

Interestingly, firm D's past advertising behavior which is accumulated and periodically weighted in our goodwill measure impacts B's decision negatively. This implies that there may be spillover effects of goodwill. Based on the nested logit model we have adopted we can identify two opposing effects of an increase in the goodwill level of a competitor. First, it increases size of the population which buys liquid detergents. Second, it reduces the market share of all the other competitors. Our negative estimate for the goodwill level of firm D in the advertising strategy of firm B suggests that the first effect may be important. Another interpretation is due to the fact that a firm should advertise more heavily to keep the sales constant when the goodwill level of a competitor increases. That is, when a competitor commands a high goodwill level, the effectiveness of advertising by firm B on its sales may be lower. The negative estimate we obtain might be due to a combination of the positive effects of competitor advertising on market size - which reduces the need to advertise to increase sales - as well as the negative effect of of the competitor's goodwill level on the effectiveness of advertising by firm B.

When firm B is not campaigning, it lets its goodwill level to depreciate until either advertising costs fall back down warranting the start of a new campaign, or until the goodwill stock of brand D goes up sufficiently reducing relative attractiveness of brand B. However, brand B does not seem to be concerned about the advertising by brand A as suggested by the insignificant estimate of the dummy for year 1998 . In contrast, in year 2000, brand B apparently shifted its advertising strategy due to the introduction of a new product in a related category. The negative estimate for the coefficient of the dummy implies a downward shift of firm B's advertising budget which in turn implies less advertising intensity in the liquid detergents category. The fact that the advertising costs, competitor's goodwill and competitive environment have a genuine impact on the end or start of a campaign suggests that the threshold values, $(S, s)$, may also be state dependent. Analysis of such rules, which have been studied in different contexts in Cheng and Sethi (1999) and Hall and Rust (2000), in advertising could prove a fruitful area of future research. 

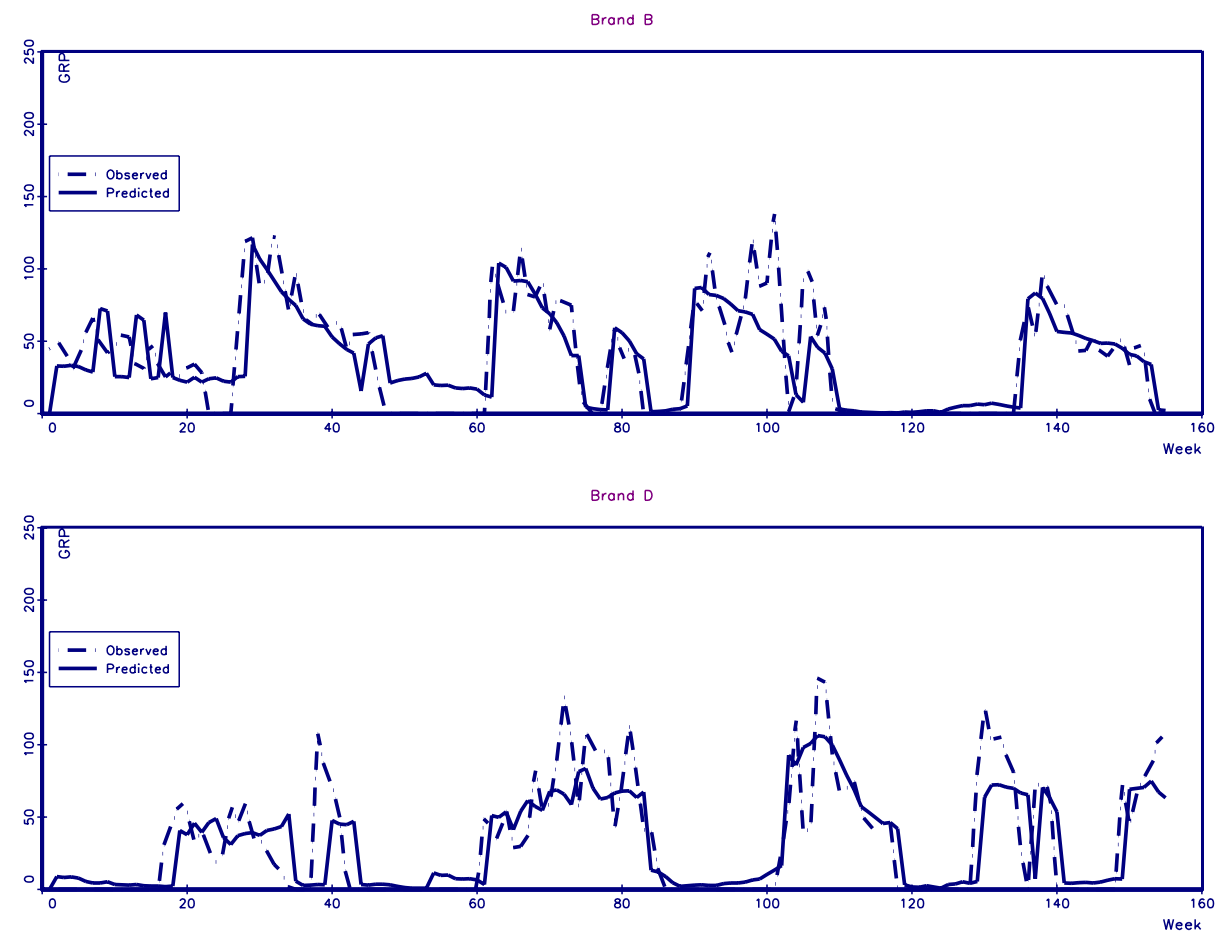

Figure 3: Observed and predicted GPP-levels of Brand B and D

We used the parameters to predict B's GRP choices and plotted them as well as the true GRP realization of B in Figure 3. The plot verifies the ability of our simple model to explain observed goodwill levels. Of course in some periods the predicted GRP-levels seem to be off the mark, e.g. in the periods around the 100th week. This might be due to the fact that the true advertising cycle from 88th to the 110th week looks different from the other cycles of brand B. We now turn to the parameter estimates of brand D.

\section{Explaining the dynamic advertising strategy of firm D}

We present the estimation results regarding firm D's advertising policy in Table 5. Similar to brand B, models that are just based on plain goodwill level. i.e. models 7 and 8 , perform once again very poorly. Similar to brand B, the main determinants of the advertising policy of brand $\mathrm{D}$ turns out to be a campaign indicator, advertising costs and competitor's goodwill. However, brand D's own goodwill level does not seem to play an important role beyond affecting the campaign indicator. We favor 
Table 5: Estimation results of the tobit models for brand D

\begin{tabular}{|c|c|c|c|c|c|c|c|c|}
\hline variable & Model 1 & Model 2 & Model 3 & Model 4 & Model 5 & Model 6 & Model 7 & Model 8 \\
\hline intercept & $\begin{array}{l}144.3584 \\
(36.3250)\end{array}$ & $\begin{array}{c}26.0390 \\
(29.7188)\end{array}$ & $\begin{array}{c}32.8219 \\
(30.5539)\end{array}$ & $\begin{array}{c}31.1548 \\
(28.4938)\end{array}$ & $\begin{array}{c}36.7926 \\
(29.3037)\end{array}$ & $\begin{array}{c}33.6517 \\
(30.6206)\end{array}$ & $\begin{array}{c}-8.8080 \\
(13.2940)\end{array}$ & $\begin{array}{l}-17.6588 \\
(14.3971)\end{array}$ \\
\hline$C P M_{j t}$ & $\begin{array}{l}-6.9985 \\
(1.9540)\end{array}$ & $\begin{array}{l}-2.9536 \\
(1.5143)\end{array}$ & $\begin{array}{l}-3.2390 \\
(1.5473)\end{array}$ & $\begin{array}{l}-3.9381 \\
(1.4963)\end{array}$ & $\begin{array}{l}-4.1742 \\
(1.5277)\end{array}$ & $\begin{array}{l}-3.9458 \\
(1.5424)\end{array}$ & & \\
\hline$C I_{j}(t)$ & & $\begin{array}{l}90.9009 \\
(9.8677)\end{array}$ & $\begin{array}{c}95.6675 \\
(12.0662)\end{array}$ & $\begin{array}{l}88.3568 \\
(9.4141)\end{array}$ & $\begin{array}{c}93.1940 \\
(11.4766)\end{array}$ & $\begin{array}{c}94.2573 \\
(11.6625)\end{array}$ & & \\
\hline$C I_{j}(t) G_{j, t-1}$ & & & $\begin{array}{l}-0.3608 \\
(0.4692)\end{array}$ & & $\begin{array}{l}-0.3418 \\
(0.4465)\end{array}$ & $\begin{array}{l}-0.4161 \\
(0.4622)\end{array}$ & & \\
\hline$G_{j^{\prime}, t-1}$ & & & & $\begin{array}{c}0.8355 \\
(0.2833)\end{array}$ & $\begin{array}{c}0.8346 \\
(0.2831)\end{array}$ & $\begin{array}{c}0.8063 \\
(0.2837)\end{array}$ & & \\
\hline$\xi_{j t}$ & & & & & & $\begin{array}{c}26.0200 \\
(35.1912)\end{array}$ & & \\
\hline$c_{j t}$ & & & & & & $\begin{array}{c}6.7644 \\
(19.7701)\end{array}$ & & \\
\hline$G_{j, t-1}$ & & & & & & & $\begin{array}{c}1.5252 \\
(0.5087)\end{array}$ & $\begin{array}{c}4.0433 \\
(1.5842)\end{array}$ \\
\hline$G_{j, t-1}^{2}$ & & & & & & & & $\begin{array}{l}-0.0596 \\
(0.0352)\end{array}$ \\
\hline$D^{1998}$ & $\begin{array}{l}-63.2216 \\
(16.2855)\end{array}$ & $\begin{array}{l}-36.4961 \\
(12.5022)\end{array}$ & $\begin{array}{l}-39.7050 \\
(13.2502)\end{array}$ & $\begin{array}{l}-56.3528 \\
(13.8508)\end{array}$ & $\begin{array}{l}-59.5718 \\
(14.4833)\end{array}$ & $\begin{array}{l}-62.9651 \\
(15.0132)\end{array}$ & $\begin{array}{l}-15.4143 \\
(14.6593)\end{array}$ & $\begin{array}{l}-19.3600 \\
(14.7097)\end{array}$ \\
\hline$D^{2000}$ & $\begin{array}{c}-3.0024 \\
(13.6949) \\
\end{array}$ & $\begin{array}{c}-5.2692 \\
(10.4845) \\
\end{array}$ & $\begin{array}{c}-7.2232 \\
(10.7575) \\
\end{array}$ & $\begin{array}{c}-5.1065 \\
(10.1069) \\
\end{array}$ & $\begin{array}{c}-6.9611 \\
(10.3878) \\
\end{array}$ & $\begin{array}{c}-8.6122 \\
(11.3633) \\
\end{array}$ & $\begin{array}{c}18.4795 \\
(13.5736) \\
\end{array}$ & $\begin{array}{c}9.2154 \\
(14.4494) \\
\end{array}$ \\
\hline$\overline{\mathrm{LL}}$ & -495.113 & -446.362 & -445.890 & -441.982 & -441.689 & -441.313 & -496.485 & -495.052 \\
\hline $\mathrm{BIC}$ & 1010.374 & 917.909 & 922.002 & 914.186 & 918.637 & 927.959 & 1013.118 & 1015.289 \\
\hline
\end{tabular}

Standard errors of the parameters are given in parenthesis

model 4 based on BIC criterion. As can be seen in the bottom panel of Figure 3, this simple model seems to explain observed behavior quite well.

The fact that brand D's own goodwill level does not seem to affect the advertising suggests that this firm follows a policy in the spirit of the policies derived by Hahn and Hyun (1991). When the competitors goodwill level and the advertising costs remain constant, brand D adopts a constant level of advertising during a campaign as well. However, the significant coefficient estimates of the advertising costs and competitor's goodwill suggest that the firm adjusts its policy away from its constant level based on these variables. Our production function specification implies that once a sufficiently high level of goodwill is attained, at a constant level of advertising goodwill stock will not increase. At such a goodwill level, our estimates imply that 
when advertising costs increase, brand D will cease its advertising campaign.

An interesting point to note is the positive coefficient we estimate for the goodwill level of firm $\mathrm{B}$ in contrast to the negative one of brand $\mathrm{D}$ when explaining brand B's advertising. That is, high goodwill of the market leader induces the smaller firm, brand $\mathrm{D}$, to advertise more. Thus, it seems that the positive effect of higher goodwill commanded by brand B on total market size is overwhelmed by its negative effect on firm D's market share in the liquid detergent category. Thus, to defend its brand value relative to that of brand $\mathrm{B}$, firm $\mathrm{D}$ chooses a higher advertising intensity. On the other hand, the negative estimate of the year 1998-dummy suggests that brand $\mathrm{D}$ is not too worried about losing market share to brand A, and, much like the behavior of firm B against advertising by itself, it reduced its advertising in this year as a response to advertising by brand A. On the other hand, the insignificant estimate of the dummy for year 2000 implies that firm D has run independent media campaigns of its liquid detergent and the new product it has introduced that year.

\section{Some advertising policy experiments}

The last step of analysis of the dynamic advertising behavior is to use the estimated parameters for a policy experiment. We initialized the goodwill of each brand by its calibrated value of the first week. Given the observed costs across the entire period of 156 weeks we used the parameter estimates of model 5 for brand B and model 4 for brand D to simulate the GRP strategies of both brands. For each period we calculate the GRP level brand B and D would pick given the controllable and uncontrollable state variables.

The plots in Figure 4 demonstrate how the advertising strategy of both brands are related to goodwill. At the start of a campaign and at low levels of goodwill a firm wants to advertise. Once a firm reaches the 'target' goodwill it stops campaigning. Goodwill depreciates until firms want to advert again. We also plotted the simulated GRP strategies of the two brands against the observed GRP choices of the brands. One can verify that the simulated GRP strategies are not too different from the observed ones. Note, however, that the simulated GRP choice do not reflect an in sample fit. The simulated values only depend on the GRP levels of the first week. 

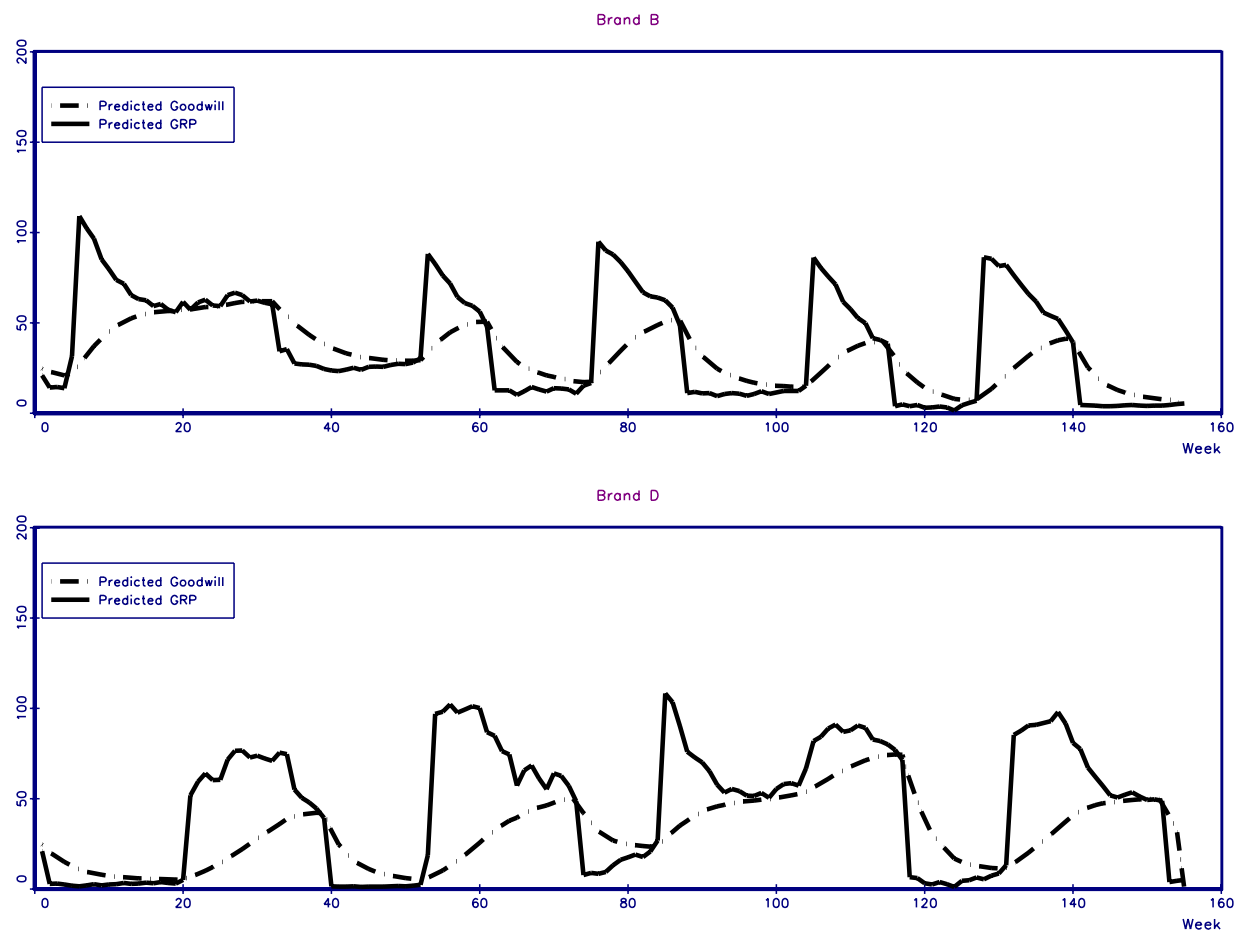

Figure 4: Simulated goodwill levels and corresponding GRP strategies of B and D
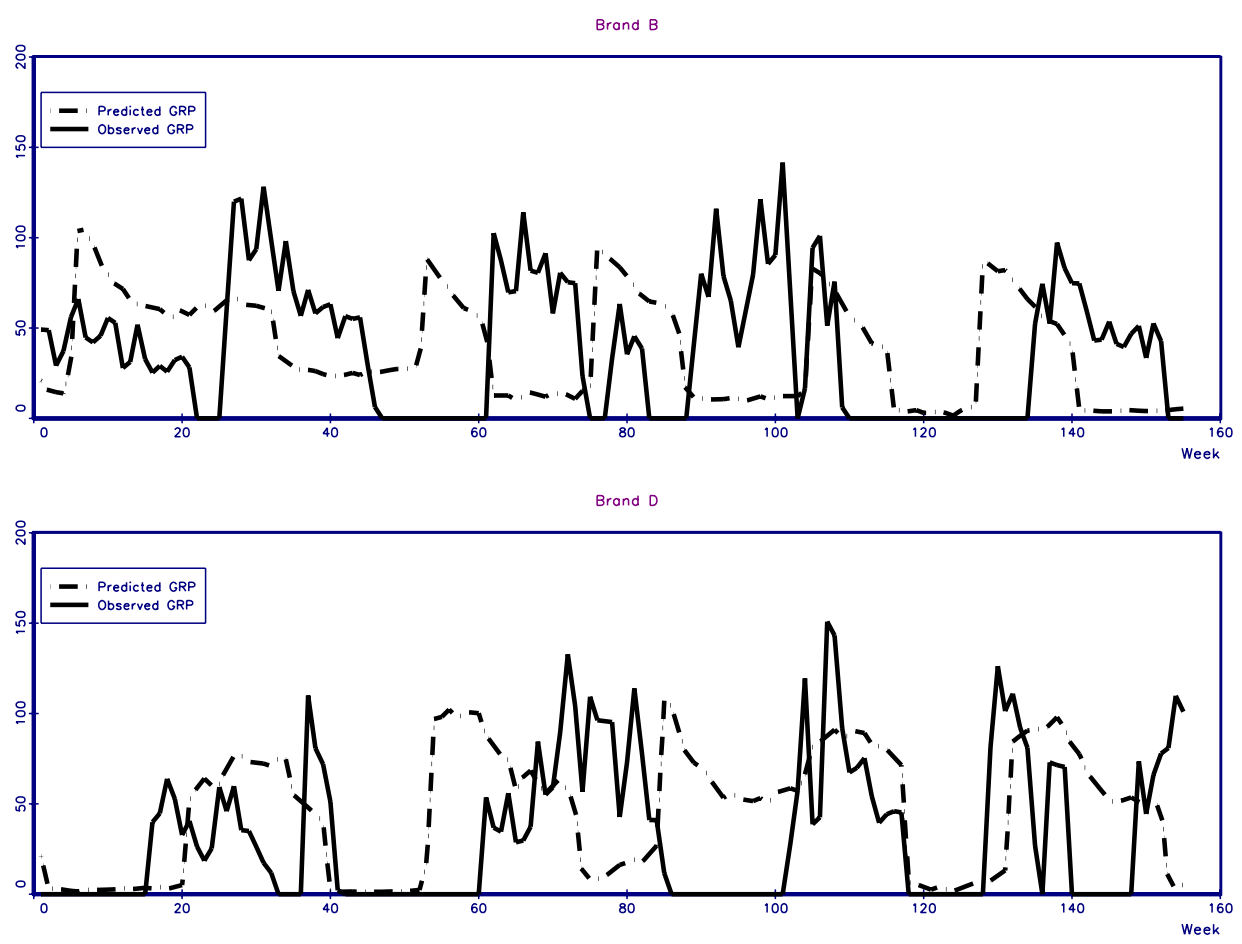

Figure 5: Simulated GRP strategies and observed GRP strategies of B and D 


\section{Conclusion}

In this paper, we have presented a simple model to analyze advertising behavior in a consumer goods market empirically. We start by assuming that firms advertise in order to increase their brand value through increasing their goodwill. Given the fact that goodwill is a consumer state that is not directly observable, we introduce a methodology to indirectly infer goodwill levels. The approach is based on specifying a demand function which shifts with changes in goodwill, and a goodwill production function that describes the accumulation of goodwill. Conditional on these specifications, we can identify the parameters of demand and the goodwill production function by a series of simple transformations of the demand functions. Using the estimated parameters and information on advertising levels prior to our sample period, we construct goodwill levels.

We then use these filtered goodwill levels, in analyzing advertising behavior. Even though we follow a reduced form approach, we introduced a model of dynamic advertising competition to guide our empirical study. Using the properties of a Markov Perfect Equilibrium, we identify variables that should have an impact on advertising intensity. We then use these variables to determine the main drivers of advertising. We confirm in our empirical study that goodwill plays an important role when firms formulate their advertising strategies.

We have documented that simple policies based on goodwill levels fail and are outperformed by those policies which control for being in a campaign, level of advertising costs as well as competitor's goodwill levels. The overwhelming empirical support for such policies suggest the need to account for campaigning decisions. Surprisingly, the theoretical literature on advertising has ignored this link between advertising levels and campaigning. The implied form of a modified $(S, s)$ type policy in our empirical study, suggests that fixed costs as well as other factors influencing the competitive landscape might have important influences on advertising behavior. 


\section{References}

Basar, T. and Oldser, G. (1982). Dynamic noncooperative game theory. New York, Academic Press.

Berry, S. T. (1994). Estimating discrete choice models of product differentiation. RAND Journal of Economics 25, 242-262.

Besanko, D., Gupta, S. and Jain, D. (1998). Logit demand estimation under competitive pricing behavior: An equilibrium framework. Management Science 44(Part 1 of 2$), 1533-1547$.

Bresnahan, T. F. (1989). Empirical studies of industries with market power. In: Schmalensee, R. and Willig, R. D. (eds.), Handbook of Industrial Organization, Elsevier Science Publisher B. V., 1011-1057.

Cardell, N. S. (1991). Variance components structures for the extreme value and logistic distributions. Mimeo, Washington State University.

Cheng, F. and Sethi, S. (1999). A periodic review inventory model with demand influenced by promotion decisions. Management Science 45, 1510-1523.

Chintagunta, P. K. and Vilcassim, N. J. (1992). An empirical investigation of advertising strategies in a dynamic duopoly. Management Science 38, 1230-1244.

Deal, K. R. (1979). Optimizing advertising expenditures in a dynamic duopoly. Operations Research 27, 682-692.

Doraszelski, U. and Markovich, S. (2004). Advertising dynamics and competitive advantage. Working Paper, July 30, 2004.

Dube, J.-P., Hitsch, G. J. and Manchanda, P. (2003). An empirical model of advertising dynamics. Working Paper, Dezember 2003.

Erickson, G. M. (1985). A model of advertising competition. Journal of Marketing Research 22, 297-304. 
Erickson, G. M. (1992). Empirical analysis of closed-loop duopoly advertising strategies. Management Science 38, 1732-1749.

Erickson, G. M. (1995). Advertising strategies in a dynamic oligopoly. Journal of Marketing Research 32, 233-237.

Espinosa, M. P. and Mariel, P. (2001). A model of optimal advertising expenditures in a dynamic duopoly. Atlantic Economic Journal 29, 135-161.

Feinberg, F. M. (2001). On continuous-time optimal advertising under S-shaped response. Management Science 47, 1476-1487.

Fruchter, G. E. and Kalish, S. (1997). Closed-loop advertising strategies in a duopoly. Management Science 43, 54-63.

Hahn, M. and Hyun, J. (1991). Advertising cost interactions and the optimality of pulsing. Management Science 37, 157-169.

Hall, G. and Rust, J. (2000). The (S,s) rule is an optimal trading strategy in a class of commodity price speculation problems. Working Paper, Yale University, March 2000 .

Hausman, J. A. (1978). Specification tests in econometrics. Econometrica 46, 12511271.

Klapper, D. and Doganoglu, T. (2004). Product variety and competitive pricing in consumer goods markets. mimeo.

Mahajan, V. and Muller, E. (1986). Advertising pulsing policies for generating awareness for new products. Marketing Science 5, 89-111.

Maskin, E. and Tirole, J. (1988). A theory of dynamic oligopoly, I: Overviwe and quantity competition with large fixed costs. Econometrica 56, 549-569.

McFadden, D. (1978). Modeling the choice of residential location. In: Spatial Interaction Theory and Planing Models, Karlgvist, A. et al., (Eds.), Amsterdam, North Holland. 
Mesak, H. I. (1999). On the generalizability of advertising pulsation monopoly results to an oligopoly. European Journal of Operational Research 117, 429-449.

Mesak, H. I. and Calloway, J. A. (1995a). A pulsing model of advertising competition: a game theoretic approach, part A - Theoretical foundation. European Journal of Operational Research 86, 231-248.

Mesak, H. I. and Calloway, J. A. (1995b). A pulsing model of advertising competition: a game theoretic approach, part B - Empirical application and findings. European Journal of Operational Research 86, 422-433.

Mesak, H. I. and Darrat, A. F. (1992). On comparing alternativ advertising policies of pulsation. Decision Sciences 32, 541-564.

Pakes, A. and McGuire, P. (1994). Computing markov-perfect nash equilibria: Numerical implications of a dynamic differentiated product model. RAND Journal of Economics 25, 555-589.

Rao, R. C. (1990). Impact of competition on strategic marketing decisions. In: Interface of Marketing and Strategy, by Day. G. and Weitz, B. and Wensley, R. (Eds.), JAI Press, Greenwich, CT 1990.

Sasieni, M. W. (1971). Optimal advertising expenditure. Management Science 18(Part II), 64-72.

Sasieni, M. W. (1989). Optimal advertising strategies. Marketing Science 8, 358-370.

Sorger, G. (1988). Competitive dynamic advertising: a modification of the case game. Journal of Economic Dynamics and Control 13, 55-80.

Sudhir, K. (2001). Structural analysis of manufacturer pricing in the presence of a strategic retailer. Marketing Science 20, 244-264.

Tellis, G. J. and Weiss, D. L. (1995). Does TV advertising really affect sales? The role of measures, models, and data aggregation. Journal of Advertising 24, Page $1-12$. 
Vakratsas, D. and Ambler, T. (1999). How advertising works: What do we really know? Journal of Marketing 63, 26-43.

Vakratsas, D., Feinberg, F. M., Bass, F. M. and Kalyanaram, G. (2004). The shape of advertising response functions revisited: A model of dynamic probabilistic thresholds. Marketing Science 23, 109-119.

Villas-Boas, J. M. (1993). Predicting advertising pulsing policies in an oligopoly: A model and empirical test. Marketing Science 12, 88-102.

Villas-Boas, J. M. and Winer, R. S. (1999). Endogeneity in brand choice models. Management Science 45, 1324-1338. 